\title{
Hormones and Auditory Perception: Study of Dichotic Listening in Women during the Menstrual Cycle
}

\author{
Cláudia da Silva Carneiro ${ }^{1}$ Anna Alice Figueiredo de Almeida ${ }^{1}$ Angela Ribas ${ }^{2}$ Karolina Kluk-De Kort ${ }^{3}$ \\ Daviany Oliveira Lima ${ }^{1}$ Aline Menezes Guedes Dias de Araújo ${ }^{1}$ Danilo Augusto de Holanda Ferreira ${ }^{4}$ \\ Mariana Lopes Martins ${ }^{1}$ Thais Mendonça Maia Wanderley Cruz Freitas ${ }^{1}$ Marine Raquel Diniz de Rosa ${ }^{1}$
}

\footnotetext{
1 Department of Speech Therapy, Centro de Ciências da Saúde, Universidade Federal da Paraíba, João Pessoa, Brazil

2 Post-Graduation Program in Communication Disorders,

Universidade Tuiuti do Paraná, Curitiba, Paraná, Brazil

${ }^{3}$ School of Psychological Sciences, University of Manchester,

Manchester, Greater Manchester, United Kingdom of Great Britain and Northern Ireland

${ }^{4}$ Instituto Federal de Educação, Ciência e Tecnologia da Paraíba

(IFPB), João Pessoa, Paraíba, Brazil
}

Int Arch Otorhinolaryngol 2019;23:70-76.

\begin{abstract}
Address for correspondence Marine Rosa, PhD, Departamento de Fonoaudiologia, Centro de Ciências da Saúde, Universidade Federal da Paraíba, Cidade Universitária, João Pessoa, Paraíba, 58051-900, Brazil (e-mail: mrdrosa@yahoo.com.br).
\end{abstract}

\section{Abstract \\ Keywords \\ - auditory perception \\ - dichotic listening \\ - speech therapy \\ - menstrual cycle \\ - estrogen}

Introduction Dichotic listening refers to the ability to hear different sounds presented to each ear simultaneously.

Objective The aim of the present study was to assess dichotic listening in women throughout the menstrual cycle.

Methods The volunteers who met the eligibility criteria participated in a dichotic listening assessment composed of three tests: 1 ) staggered spondaic word test; 2 ) dichotic digits test; and 3) consonant-vowel test. The female participants were tested during two different phases of the menstrual cycle: the follicular (days 11 to 13) and luteal (days 23 to 26 ) phases. The phases were confirmed by measuring serum levels of the hormone estradiol.

Results A total of 20 volunteers aged 18 to 49 years participated in the study (9 females and 11 males). In test 1 , only the right ear of females showed better performance during the follicular phase (high estrogen levels), compared with the luteal phase (low estrogen levels); in test 2, there were no significant differences for any of the groups; and in test 3 , both males and females showed significantly better performance in their right ear compared with their left ear.

Conclusion The better performance of females during the follicular phase of the cycle may indicate that estrogen levels might have an influence on dichotic listening in women.

\section{Introduction}

The perceptual processing of acoustic signals involves encoding and transforming acoustic cues into neural signals. While both processes are limited by the structures of the auditory system, auditory responses are driven and modulated by neurotransmitters and neuromodulatory systems. ${ }^{1}$

Recent evidence suggests that the hormone estrogen might influence the auditory function at different levels of the central auditory system (CAS) by acting as a direct modulator of received

September 1, 2017

accepted

December 17, 2017

published online

May 9, 2018
DOI https://doi.org/

10.1055/s-0038-1626701. ISSN 1809-9777.
Copyright $\odot 2019$ by Thieme Revinter

Publicações Ltda, Rio de Janeiro, Brazil
License terms

(요 (1) $\Theta \circledast$ 
central auditory neurons via rapid modifications in neuronal excitability. $^{1-3}$ If so, the fluctuation in estrogen levels during the menstrual cycle might influence auditory perception ${ }^{3}$ by acting as a non-traditional neuromodulator. ${ }^{2}$

Studies have used dichotic tests to investigate changes in perceptual asymmetry as a function of the menstrual cycle phase, ${ }^{4-8}$ and found right-ear advantage in the presence of high estrogen levels. ${ }^{5-7}$

Dichotic listening tests, which involve presenting different auditory stimuli to each ear simultaneously, ${ }^{9}$ have been considered a standard approach to investigate functional asymmetries in speech perception. ${ }^{10}$ Stimuli presented to the right ear are transmitted through the contralateral pathway to the left hemisphere, where they are processed, and stimuli presented to the left ear are transmitted through the contralateral pathway to the right hemisphere, through the corpus callosum, and then, to the left hemisphere, where they are processed. ${ }^{11}$

The present study aimed to establish scientific evidence for the effects of gonadal steroid hormones (estrogen) on the symmetry of auditory perception using dichotic listening tests. In addition to the consonant-vowel test, we applied the dichotic digits (DD) and the staggered spondaic word (SSW) tests; despite targeting the same functions, these tests have not been used before in studies of the effects of hormones on auditory perception. Additionally, the level of plasma estradiol was measured to confirm the phases of the menstrual cycle.

Because of the inconsistencies in the literature, new studies with great methodological rigor are needed to determine the actual effect of estrogen on dichotic listening during the menstrual cycle. Therefore, the aim of the present study was to characterize dichotic listening in women during the phases of the menstrual cycle.

\section{Method}

\section{Design and Subjects}

A cohort, longitudinal, blinded study was conducted. The researchers, who were evaluating the volunteers, were blinded to the menstrual phase of the participants at the moment of the dichotic tests.

The sample was composed of 20 participants aged 18 to 49 years old (mean $[M]=25$; standard deviation $[S D]=15$ ), including 9 women (the experimental group) and 11 men (the control group). The participants were recruited among undergraduate students at a higher education institution using convenience sampling. We used the control group of men, since men do not present monthly hormonal variations such as women.

The participants had normal findings on otoscopy, normal hearing, a type-A tympanogram, and presented ipsilateral and contralateral reflexes. None of them had auditory processing complaints or were using hormone-containing medications during the study period or in the previous six months. Moreover, they were unaware of having any hormone dysfunction; with right-hand dominance; and without any neurologic, cognitive or communication disorder that would impair their performance on the required tests. In addition, the women had to: exhibit regular menstrual cycles (27 to 32 days); not be pregnant or breastfeeding in the previous six months; and have estradiol levels within the expected normal limits for each investigated phase (follicular: 38-649 pg /mL; and luteal: 21-312 pg /mL).

\section{Phases of the Menstrual Cycle}

In the present study, the phases were defined as follows: early follicular (days 1 to 7 ), late follicular (days 8 to 13), early luteal (days 14 to 22), and late luteal (days 23 to 28). The samples were taken at the following time-points: between days 11 to 13 (called follicular phase), when the estrogen levels are high; and between days 23 to 26 (called luteal phase), when the estrogen levels are low.

The length of the luteal phase is usually 14 days on average, regardless of the length of the other phases, with ovulation occurring up to 14 days before the onset of menstruation. This provides an estimate of the menstrual cycle phase and the optimal days for testing; the interval in which the different phases were examined was counted backwards from the first day of the expected onset of the next menses. ${ }^{12}$

In order to confirm the menstrual phase, blood samples were taken at days 11-13 (late follicular phase) and 23-26 (late luteal phase) to measure estradiol levels.

\section{Measurements}

The following auditory and hormonal measurements were performed:

\section{Basic Audiological Evaluation}

A basic audiological evaluation (clinical interview, otoscopy, and pure-tone, speech and impedance audiometry) was performed to confirm clinically normal hearing.

Air-conducted pure tone audiometry (PTA), using the ADD 229 audiometer (Interacoustics, Middlefart, Denmark) in an acoustic test chamber, was performed at frequencies from $250 \mathrm{~Hz}$ to $8,000 \mathrm{~Hz}^{13}$

Speech audiometry comprised speech recognition and intelligibility tests (speech reception threshold [SRT] and speech recognition percent index [SRPI]). The SRT was used to establish the lowest intensity at which the volunteers were able to identify $50 \%$ of the words on a list presented to them. The SRPI was used to assess the volunteers' ability to correctly repeat a list of monosyllabic and disyllabic words presented at a fixed and comfortable level. ${ }^{14}$ Impedance audiometry was performed with an Interacoustics AT 235 middle ear analyzer.

\section{Evaluation of Dichotic Listening}

The volunteers who met the inclusion criteria underwent a dichotic listening assessment using the SSW, DD and dichotic consonant-vowel (CV) tests. ${ }^{15,16}$

The SSW test comprises 40 verbal stimuli, each composed of 4 disyllabic paroxytone words, for a total of 160 words. The volunteers were instructed to listen attentively to the fourword groups and to repeat the words aloud in order at the 
end of each presentation. The responses were recorded on the test-response form by the investigator. Any omission, replacement or distortion of a word was counted as an error. The SSW test enables the assessment of skills related to the auditory figure-background skill and the temporal ordering of speech sounds. ${ }^{15,16}$

The results of the SSW test were analyzed both quantitatively and qualitatively. In the quantitative analysis, the number of errors (omission, replacement and distortion) in each column of word at the performance table (columns A to $\mathrm{H}$ ) was counted and transformed into subscores: $\mathrm{AH}$ (right non-competing [RNC]), BG (right competing [RC]), CF (left competing $[\mathrm{LC}]$ ) and $\mathrm{DE}$ (left non-competing[LNC]), which were then transformed into percentages. The result represented the percentage of errors relative to each ear.

The percentage of hits was calculated based on the total percentage of errors, and was used to establish the degree of auditory perception ability assessed, ${ }^{15,16}$ which is defined as "normal" when a hit rate of $90 \%$ or higher is reached among individuals aged 9 years or older.

In the qualitative analysis, the following trends of errors were analyzed: low/high auditory effect or high/low ordering effect (indicative of auditory memory defects); high/low auditory effect or low/high ordering effect (indicative of auditory analysis and synthesis abnormality); type-A pattern (indicative of sound-symbol association problems); and inversions (indicative of memory defects for sequences of verbal sounds). ${ }^{15,16}$

Next, the DD test was performed to assess hearing under divided attention. The test uses a list of 20 stimuli, each composed of 4 digits selected $(4,5,7,8$ or 9 ), which are disyllabic in the Portuguese language. Two different digits were presented to each ear simultaneously. Before the testing began, the volunteers were instructed to listen attentively to the 4-digit groups ( 2 in each ear) and to repeat the digits aloud in any order at the end of each presentation. Any omission or replacement of a digit was counted as an error. The DD test enables the assessment of verbal figure-background skills. ${ }^{15,16}$

The results of the DD test were expressed as the percentage of hits. The normality criterion required $95 \%$ or more hits in individuals aged 11 years or older.

Finally, the CV test was performed. This test comprises twelve stimuli, each composed of pairs of different syllables. For each stimulus, the two syllables were presented simultaneously, one in each ear. The participants were instructed to listen attentively to the syllables and repeat them aloud at the end of each presentation. Any omission or replacement of a syllable was counted as an error. The CV test enables the assessment of verbal sound figure-background skills. ${ }^{15,16}$

All three dichotic tests were performed at the level of $50 \mathrm{~dB}$ SL (above the average air pure-tone thresholds at the frequencies of $500 \mathrm{~Hz}, 1,000 \mathrm{~Hz}$ and $2,000 \mathrm{~Hz}$ ).

All tests were performed in an acoustic booth using an appropriately calibrated Acústica Orlandi (Bauru, São Paulo, SP, Brazil) PA2004 mixing desk and Acústica Orlandi TDH 39 headphones. The stimuli were played from a $C D^{15,16}$ in a
Toshiba (Minato, Tokyo, Japan) compact disc player coupled to the mixing desk.

\section{Hormone Evaluation}

Blood samples were collected during the follicular (days 11-14) and luteal (days 23-26) phases of the menstrual cycle. All sample collections and analyses were performed at the Clinical Analysis Laboratory of the University Hospital in the city of João Pessoa, Paraíba, Brazil. The estradiol levels were measured using the Architect Estradiol commercial kit, which is a chemiluminescent microparticle immunoassay performed with an Abbott Architect i2000 analyzer (Illinois, USA).

The samples were always collected at the same time, between 7 and 9 Am (after at least 4 hours of fasting).

\section{Procedures}

The female participants (the experimental group) were tested on two different days according to the phase of the menstrual cycle, as follows:

- late follicular phase, corresponding to the period of high estrogen levels.

- late luteal phase, corresponding to the period of low estrogen levels.

The male participants (the control group) were also tested on 2 different days, with a 10- to 15-day interval between tests.

The women (the experimental group) underwent blood plasma collection and dichotic listening assessments at each phase (twice) of the menstrual cycle. The men (the control group) underwent the dichotic listening assessment only. The audiologist measuring the PTA did not know in which phase of the cycle the women were.

All of the participants were tested at approximately the same time of day (with a maximum difference of $2 \mathrm{~h}$ ) to minimize the effects of diurnal and circadian hormone variations. $^{17}$

The data were analyzed using the Statistical Package for Social Sciences (SPSS, IBM Corp., Armonk, NY, US) software, version 20.0. The significance level was set at $5 \%(p<0.05)$.

\section{Ethics}

The study was approved by the Human Research Ethics Committee of the Center of Health Science in Brazil, under protocol no. 0657/13. All of the participants signed an informed consent form that complied with the National Committee on Research Ethics resolution no. 196/96 and the National Health Council resolution no. 466/2012.

\section{Results}

The estradiol levels of the participants in the experimental group (the women) at both investigated phases of the menstrual cycle were analyzed. The difference in estradiol levels between the 2 phases was statistically significant $(p=0.005)$, and was higher in the follicular phase $(\mathrm{M}=208.20 ; \mathrm{SD}=146.20)$ than in the luteal phase $(\mathrm{M}=118.40 ; \mathrm{SD}=91.60)($ - Table 1$)$. 
Table 1 Descriptive statistics corresponding to the participants' estradiol levels during both phases of the menstrual cycle

\begin{tabular}{|l|l|l|l|}
\hline Values (unit) & Follicular phase & Luteal phase & p-value \\
\hline Mean & 208.20 & 118.40 & \multirow{2}{*}{$0.005^{*}$} \\
\cline { 1 - 2 } SD & 146.26 & 91.60 & \\
\cline { 1 - 3 } Median & 230.50 & 107.50 & \multirow{1}{*}{} \\
\cline { 1 - 2 } IQR & 236.00 & 114.00 & \\
\hline Minimum & 20.00 & 10.00 & \\
\hline Maximum & 467.00 & 311.00 & \\
\hline
\end{tabular}

Abbreviations: IQR, interquartile range (75-25\%); SD, standard deviation.

Note: ${ }^{*}$ Significant difference $(p<0.05)$ on the paired Wilcoxon test.

In the experimental group, the quantitative SSW test results for each ear differed significantly between the two phases $(p=0.045)$, and the performance of the right ear during the follicular phase was better ( - Tables 2 and $\mathbf{3}$ ).

The results of the CV test did not indicate any significant difference between phases/sessions in either ear. However, the comparison of ears within the same phase/session showed that the performance of the right ear (follicular: $\mathrm{M}=13.90 ; \mathrm{SD}=2.47$; luteal: $\mathrm{M}=13.50 ; \mathrm{SD}=1.9$ ) was significantly ( $p=0.001$ ) better than that of the left (follicular: $\mathrm{M}=6.80 ; \quad \mathrm{SD}=3.58 ;$ luteal: $\mathrm{M}=7.30 ; \mathrm{SD}=2.79$ ) (-Table 4).

No significant difference in the percentage of hits for the DD test was found between the ears or between phases/ sessions (-Table 5).

\section{Discussion}

Some recent studies ${ }^{4,6,7,10,18-20}$ have attempted to investigate the influence of ovarian steroidal hormones on dichotic listening.
The results of the SSW test indicated that in the experimental group (women), the performance of the right ear was better during the follicular phase compared with the luteal phase. No study using the SSW test could be found in the literature. However, a study ${ }^{18}$ applied a test that included a dichotic word task (event-related potential [ERP]), and found that the latency of response was shortest in the right ear (left hemisphere) during the follicular phase, when estradiol levels were elevated.

The high estradiol levels during the follicular phase influence auditory performance; thus, the better performance of the right ear during the follicular phase might be associated with these high levels. Estradiol is described in the literature as a direct modulator of the central auditory neurons (GABAergic, serotonergic and glutamatergic); it induces an excitatory effect on the auditory and central nervous system fibers in addition to exhibiting neuroprotective and antioxidant actions. ${ }^{1-3}$

Thus, estrogen levels might affect the reactivity of the brain's arteries to vasoactive stimuli, such as serotonin, in addition to influencing the cochlear blood flow and the consequent changes in the metabolite inflow to the information-processing cells. ${ }^{2}$

It may be more specifically argued that high estrogen levels reinforce left hemisphere functions, resulting in better performance of the right ear during the follicular phase. ${ }^{20}$

The relationship between estrogen and the limbic system is another factor that might account for the right ear's better performance during the follicular phase and its worse performance during the luteal phase. High estradiol levels exert a significant influence on the hippocampal regions and paraventricular nuclei because of the large number of receptors in the internal neuronal membranes. ${ }^{21}$ Such high concentrations of estrogen receptors might trigger changes in the action of neurotransmitters that can reduce the potential discharge of the action, consequently controlling emotional and behavioral activities while inversely increasing the responses that are common to the luteal phase (anxiety,

Table 2 Descriptive and comparative analysis of the variables ear and SSW condition between phases of the menstrual cycle (experimental group) and sessions (control group)

\begin{tabular}{|c|c|c|c|c|c|c|c|}
\hline \multirow{3}{*}{$\begin{array}{l}\text { Group } \\
\text { (phase/session) }\end{array}$} & \multirow[t]{3}{*}{ Ear } & \multirow{2}{*}{\multicolumn{2}{|c|}{ Value (\%) }} & \multicolumn{4}{|c|}{$p$-value ${ }^{*}$} \\
\hline & & & & \multicolumn{2}{|c|}{ Between phases } & \multicolumn{2}{|c|}{ Between ears } \\
\hline & & Mean & SD & RE & LE & Follicular & Luteal \\
\hline \multirow{2}{*}{$\begin{array}{l}\text { Women } \\
\text { (follicular) }\end{array}$} & Right & 98.75 & 2.87 & \multirow[t]{4}{*}{$0.045^{*}$} & \multirow[t]{4}{*}{0.173} & \multirow[t]{4}{*}{0.509} & \multirow[t]{4}{*}{0.085} \\
\hline & Left & 97.38 & 4.09 & & & & \\
\hline \multirow{2}{*}{$\begin{array}{l}\text { Women } \\
\text { (luteal) }\end{array}$} & Right & 97.40 & 3.17 & & & & \\
\hline & Left & 96.75 & 4.81 & & & & \\
\hline \multirow{2}{*}{$\begin{array}{l}\text { Men } \\
\text { (session 1) }\end{array}$} & Right & 94.77 & 4.25 & \multirow[t]{4}{*}{0.265} & \multirow[t]{4}{*}{0.228} & \multirow[t]{4}{*}{0.036} & \multirow[t]{4}{*}{0.028} \\
\hline & Left & 90.68 & 6.23 & & & & \\
\hline \multirow{2}{*}{$\begin{array}{l}\text { Men } \\
\text { (session 2) }\end{array}$} & Right & 96.36 & 3.23 & & & & \\
\hline & Left & 92.72 & 4.80 & & & & \\
\hline
\end{tabular}

Abbreviations: LE, left ear; RE, right ear; SD, standard deviation.

Note: *Paired Wilcoxon test. 
74 Hormones and Auditory Perception Carneiro et al.

Table 3 Descriptive statistics of the SSW test results per ear and study phase

\begin{tabular}{|c|c|c|c|c|c|c|}
\hline \multirow[t]{2}{*}{ Phase } & \multirow[t]{2}{*}{ Ear } & \multicolumn{5}{|l|}{ Value } \\
\hline & & Mean & SD & Median & Minimum & Maximum \\
\hline \multirow[t]{2}{*}{ Follicular } & Right & 98.75 & 2.87 & 100.00 & 87.50 & 100.00 \\
\hline & Left & 97.38 & 4.09 & 100.00 & 87.50 & 100.00 \\
\hline \multirow[t]{2}{*}{ Luteal } & Right & 97.40 & 3.17 & 97.50 & 87.50 & 100.00 \\
\hline & Left & 96.75 & 4.81 & 98.75 & 85.00 & 100.00 \\
\hline
\end{tabular}

Abbreviations: SD, standard deviation; SSW, staggered spondaic word test.

Note: *Paired Wilcoxon test.

Table 4 Quantitative analysis of hits on the consonant-vowel test according to group and phase of the menstrual cycle (women) or session (men)

\begin{tabular}{|c|c|c|c|c|c|c|c|}
\hline \multirow[t]{3}{*}{ Group (phase/session) } & \multirow[t]{3}{*}{ Ear } & \multirow{2}{*}{\multicolumn{2}{|c|}{ Value (\%) }} & \multicolumn{4}{|c|}{$p$-value ${ }^{*}$} \\
\hline & & & & \multicolumn{2}{|c|}{ Between phases } & \multicolumn{2}{|c|}{ Between ears } \\
\hline & & Mean & SD & RE & LE & Follicular & Luteal \\
\hline \multirow[t]{2}{*}{ Women (follicular) } & Right & 13.90 & 2.47 & \multirow[t]{4}{*}{0.533} & \multirow[t]{4}{*}{0.720} & \multirow[t]{4}{*}{$<0.001^{*}$} & \multirow[t]{4}{*}{$<0.001$} \\
\hline & Left & 6.80 & 3.58 & & & & \\
\hline \multirow[t]{2}{*}{ Women (luteal) } & Right & 13.50 & 1.90 & & & & \\
\hline & Left & 7.30 & 2.79 & & & & \\
\hline \multirow[t]{2}{*}{ Men (session 1) } & Right & 14.27 & 1.68 & \multirow[t]{4}{*}{0.098} & \multirow[t]{4}{*}{0.201} & \multirow[t]{4}{*}{$<0.001^{*}$} & \multirow[t]{4}{*}{$<0.001^{*}$} \\
\hline & Left & 5.09 & 2.26 & & & & \\
\hline \multirow[t]{2}{*}{ Men (session 2) } & Right & 13.09 & 1.70 & & & & \\
\hline & Left & 6.64 & 3.14 & & & & \\
\hline
\end{tabular}

Abbreviations: LE, left ear; RE, right ear; SD, standard deviation.

Note: *Paired Wilcoxon test.

Table 5 Percentage of hits on the dichotic digits test according to assessed ear and analyzed phase/session

\begin{tabular}{|c|c|c|c|c|c|c|c|}
\hline \multirow[t]{3}{*}{ Group (phase/session) } & \multirow[t]{3}{*}{ Ear } & \multirow{2}{*}{\multicolumn{2}{|c|}{ Value (\%) }} & \multicolumn{4}{|c|}{$p$-value* } \\
\hline & & & & \multicolumn{2}{|c|}{ Between phases } & \multicolumn{2}{|c|}{ Between ears } \\
\hline & & Mean & SD & RE & LE & Follicular & Luteal \\
\hline \multirow[t]{2}{*}{ Women (follicular) } & Right & 98.75 & 1.32 & \multirow[t]{4}{*}{0.180} & \multirow[t]{4}{*}{0.527} & \multirow[t]{4}{*}{0.550} & \multirow[t]{4}{*}{0.185} \\
\hline & Left & 98.25 & 1.69 & & & & \\
\hline \multirow[t]{2}{*}{ Women (luteal) } & Right & 99.50 & 1.05 & & & & \\
\hline & Left & 98.75 & 1.32 & & & & \\
\hline \multirow[t]{2}{*}{ Men (session 1) } & Right & 99.55 & 1.01 & \multirow[t]{4}{*}{1.000} & \multirow[t]{4}{*}{0.190} & \multirow[t]{4}{*}{0.210} & \multirow[t]{4}{*}{0.317} \\
\hline & Left & 97.95 & 3.68 & & & & \\
\hline \multirow[t]{2}{*}{ Men (session 2) } & Right & 99.55 & 1.01 & & & & \\
\hline & Left & 98.86 & 1.72 & & & & \\
\hline
\end{tabular}

Abbreviations: LE, left ear; RE, right ear; SD, standard deviation.

Note*Paired Wilcoxon test.

emotional lability and irritability), that is the premenstrual period. These factors might interfere with the subjects' responses at the time of testing, as the tests we used were subjective and required the respondents to exhibit adequate physical and mental well-being.

Regarding hearing and central nervous system issues, a study $^{22}$ evidences the influence of estrogen on the latencies of the cerebral electrical potential related to P300 events. It also shows that there is an oscillation between 265 milliseconds and 390 milliseconds, which varies in the phases of the menstrual cycle according to the concentration of estrogen.

Regarding the CV test, the percentage of hits relative to both ears remained stable across the phases of the menstrual 
cycle without any significant differences. These findings are consistent with those reported in the literature; one study using the same test throughout the menstrual cycle ${ }^{4}$ did not find significant results affecting the performance, regardless of the estrogen levels.

In contrast, other studies $6,7,19,20$ have detected significantly better performances of the right ear on the CV test during the high-estrogen phase. Taken together, the results of those studies suggest that high estrogen levels could improve left hemisphere function.

However, it should be observed that almost none of those published studies measured hormone levels via clinical procedures; instead, they defined the phases of the menstrual cycle using temporal criteria (day count) only, which might have impaired the accuracy of the identification of the phases; hence, the differences in the findings among studies. Regarding the performance of each ear, the right ear performed better on the CV test in both groups (experimental and control) and during both phases. These findings agree with the literature. A study ${ }^{4}$ also found that the right ear exhibited better performance than the left ear in all of the studied phases of the menstrual cycle.

An explanation for the right-ear advantage and the consequent left-ear disadvantage might be provided by the structural model, ${ }^{9}$ which states that information received by the right ear is directly transmitted to the left hemisphere. During dichotic stimulation, the ipsilateral pathways are suppressed, thus favoring the contralateral pathways, which have more fibers. Therefore, the left ear is at a disadvantage because of the longer transmission time required for verbal information presented to it, as the information is first conveyed to the right hemisphere and then, via the corpus callosum, to the left hemisphere, where it is processed. ${ }^{23,24}$

Regarding the DD test, no significant result was found regarding the performance of each ear as a function of the menstrual cycle phase or between ears within each phase.

A possible explanation for these findings is that verballypresented digits are more easily processed than words, not only because they are more predictable, as they are repeated several times during the test, but also because their phonological and semantic decoding might be facilitated by topdown expectations, ${ }^{25}$ leading to maximal performance irrespective of the phase of cycle.

The control group did not show any significant differences in any of the tests as a function of the assessment period.

Despite the advances in the field of hormones and auditory perception, several issues remain unexplained. In fact, there are few studies on this topic, and the existing studies show a wide variation in the methods used to measure hormone levels, and inconsistency in the nomenclature used to define the phases of the menstrual cycle, which makes comparisons among studies very difficult, if not impossible.

The present study sought to minimize these sources of bias by establishing strict eligibility criteria and well-established methods, such as measuring plasma estradiol levels to define the phases of the menstrual cycle, as hormone levels are not homogeneous among the phases. In addition, three different dichotic listening tests were used, and the results were analyzed to establish the effect of estradiol on dichotic listening.

\section{Conclusions}

The results of the present study indicate that:

- The SSW test revealed in women significantly better performance of the right ear during the follicular phase (characterized by high estrogen levels) compared with the luteal phase (characterized by low estrogen levels).

The CV test revealed significantly better performance of the right ear compared with the left ear irrespective of cycle phase (or test session in men) and sex.

The results of the present study thus suggest that estrogen may affect (improve) dichotic listening in women during the menstrual cycle.

\section{References}

1 Tremere LA, Burrows K, Jeong JK, Pinaud R. Organization of Estrogen-Associated Circuits in the Mouse Primary Auditory Cortex. J Exp Neurosci 2011;2011(05):45-60

2 Oliveira TSC. Estudo do efeito da terapia de reposição hormonal no potencial evocado auditivo de mulheres na pós-menopausa [dissertation]. Brasília: Faculdade de Ciências da Saúde; 2012

3 Tremere LA, Jeong JK, Pinaud R. Estradiol shapes auditory processing in the adult brain by regulating inhibitory transmission and plasticity-associated gene expression. J Neurosci 2009;29(18): 5949-5963

4 Cowell PE, Ledger WL, Wadnerkar MB, Skilling FM, Whiteside SP. Hormones and dichotic listening: evidence from the study of menstrual cycle effects. Brain Cogn 2011;76(02):256-262

5 Hampson E. Variations in sex-related cognitive abilities across the menstrual cycle. Brain Cogn 1990;14(01):26-43

6 Sanders G, Wenmoth D. Verbal and music dichotic listening tasks reveal variations in functional cerebral asymmetry and cognitive performance show complementary fluctuations across the menstrual cycle. Neuropsychologia 1998;36(09):869-874

7 Wadnerkar MB, Whiteside SP, Cowell PE. Dichotic listening asymmetry: sex differences and menstrual cycle effects. Laterality 2008;13(04):297-309

8 Compton RJ, Costello C, Diepold J. Interhemispheric integration during the menstrual cycle: failure to confirm progesteronemediated interhemispheric decoupling. Neuropsychologia 2004; 42(11):1496-1503

9 Kimura D. Cerebral dominance and the perception of verbal stimuli. Can J Psychol 1961;15(03):166-171

10 Hjelmervik H, Westerhausen R, Osnes B, et al. Language lateralization and cognitive control across the menstrual cycle assessed with a dichotic-listening paradigm. Psychoneuroendocrinology 2012;37(11):1866-1875

11 Bouma A, Gootjes L. Effects of attention on dichotic listening in elderly and patients with dementia of the Alzheimer type. Brain Cogn 2011;76(02):286-293

12 Jones RE, Lopez KH. The menstrual cycle. In: Jones RE, Lopez KH. Human reproductive biology. London-UK: Elsivier; 2006:73-96

13 Lloyd LL, Kaplan H. Audiometric Interpretation: A manual of basic audiometry. Baltimore1978

14 Frota S, Sampaio F. Logoaudiometria. Fundamentos em Fonoaudiologia: Audiologia: segunda edição. Rio de Janeiro: Guanabara Koogan; 2003

15 Pereira LD, Schochat E. Processamento Auditivo Central: Manual de avaliação. São Paulo: Editora Lovise; 1997

16 Pereira LD, Schochat E. Testes auditivos comportamentais para avaliação do Processamento Auditivo Central. São Paulo: Pró-Fono; 2011 
17 Lebrun CM. Effect of the different phases of the menstrual cycle and oral contraceptives on athletic performance. Sports Med 1993;16(06):400-430

18 Tillman GD. Estradiol levels during the menstrual cycle differentially affect latencies to right and left hemispheres during dichotic listening: an ERP study. Psychoneuroendocrinology 2010;35(02): 249-261

19 Altemus M, Wexler BE, Boulis N. Changes in perceptual asymmetry with the menstrual cycle. Neuropsychologia 1989;27(02): 233-240

20 Alexander GM, Altemus M, Peterson BS, Wexler BE. Replication of a premenstrual decrease in right-ear advantage on languagerelated dichotic listening tests of cerebral laterality. Neuropsychologia 2002;40(08):1293-1299
21 Edwards HE, Burnham WM, Mendonça A, Bowlby DA, MacLusky NJ. Steroid hormones affect limbic afterdischarge thresholds and kindling rates in adult female rats. Brain Res 1999;838(12):136-150

22 Fukuda Y. P300 e ciclo menstrual em mulheres jovens normais [thesis]. São Paulo: Escola Paulista de Medicina; 1993:48

23 Bellis TJ. Assessment and management of central auditory processing disorders in the educational setting. San Diego: Singular Publishing Group; 1996

24 Castro FZ, Belda RF, Prat JJB. Test de dígitos dicóticos: estudio de un caso. Acta Otorrinolaringol ESP 2008;59(10):503-505

25 Araújo S, Reis A, Faísca L. A influência da escolarização na lateralização inter-hemisférica da linguagem. Psicol Educ 2011; $1(02): 19-30$ 